\title{
Psicologia USP, 1992-2002: UMA Aventura PARTICIPATIVA $^{1}$
}

\author{
César Ades ${ }^{2}$ \\ Instituto de Psicologia - USP
}

O artigo retrata dez anos de produção da revista Psicologia USP (1992 - 2002), quando sob a coordenação de Sylvia Leser de Mello. Neste período, definiu-se, como campo básico de atuação da revista, a reflexão crítica a respeito de temas psicológicos, em contraposição à publicação de artigos empíricos e se adotou uma perspectiva multidisciplinar, concretizada na edição de números especiais (Memória, Inconsciente, Psicologia e Saúde, e outros) e dossiês (Psicanálise e Universidade, Psicologia e Razão Instrumental, e outros) dos quais tomaram parte, na busca de contrastes e convergências, pesquisadores em áreas diversas das ciências sociais e biológicas. A revista contribuiu para a manutenção da memória científica com números especiais dedicados a docentes do Instituto de Psicologia (Psicologia e Etologia, Dante Moreira Leite, $e$ outros). Esta década de esforço participativo foi importante na determinação dos rumos da revista e na preparação de Psicologia USP para novos desafios editoriais.

Descritores: Psicologia USP. Publicações em Psicologia. Instituto de Psicologia (USP).

1 Este artigo é dedicado, com admiração e carinho, a Sylvia Leser de Mello. Não pretende ser um estudo preciso e completo do desenvolvimento de Psicologia USP, na década 1992-2002, apenas um relato pessoal das boas memórias que a boa memória guardou. Peço de antemão desculpas pelas omissões e por vieses eventuais. Agradeço a Maria Helena Souza Patto e Gerson da Silva Mercês pelas sugestões sobre o conteúdo do texto e aos colegas da Comissão Editorial e a Maria Clarice Ferreira, Aparecida Angélica Z. P. Sabadini e ao próprio Gerson pelos anos de convívio e cooperação.

2 Docente do Departamento de Psicologia Experimental do Instituto de Psicologia da Universidade de São Paulo. Endereço Eletrônico: cades@usp.br 
Zi assim. Quando Sylvia Leser de Mello assumiu, em 1992, a Diretoria do Instituto de Psicologia e também ficou encarregada de dirigir a revista $P s i$ cologia USP, lembro-me de ter-lhe mandado uma mensagem com sugestões sobre conteúdos possíveis e sobre a estrutura da revista. A resposta foi rápida: por telefone e depois pessoalmente ela me convidou a fazer parte do Conselho Editorial no qual também estavam João Augusto Frayze-Pereira, Maria Cristina Machado Kupfer, Maria Helena Souza Patto, Maria Regina S. Godeli, Odette Lourenção van Kolck e Elza Corrêa Granja, então chefe do nosso Serviço de Biblioteca e Documentação. ${ }^{3}$

Quem teve a boa idéia de fundar a revista, em 1990, foi Zélia Ramozzi-Chiarottino, durante a sua gestão como Diretora. O Instituto de Psicologia ganhava, com esta iniciativa, um canal de expressão para suas pesquisas e reflexões, mas, também, porque a função de um periódico é servir de ponto de convergência para muitas contribuições externas. O primeiro artigo da revista, por sinal, tinha sido publicado em francês.

Houve, quase trinta anos antes, um revista precursora, o Jornal Brasileiro de Psicologia, fundado em 1965 pela Profa. Annita de Castilho e Marcondes Cabral como órgão da Cadeira de Psicologia da Faculdade de Filosofia, Ciências e Letras. Tinha uma capa branca com um título modesto em vermelho e o psi imprescindível num tom dourado que o tempo tornou mais escuro, nos exemplares que ainda tenho. Talvez o momento e a produção em Psicologia não fossem ainda propícios; só sei que o Jornal Brasileiro de Psicologia não foi além do terceiro volume. Recém-contratado na Cadeira, eu fazia parte do conselho de redação e é nele que publiquei meu primeiro artigo científico. Cooperar na produção de Psicologia USP teve então, para mim, o sentido de um retorno.

Relembrarei aqui os dez anos, de 1992 a 2002, nos quais participei, com Sylvia e com o resto da comissão, da aventura de produzir a revista do Instituto. Embora credenciados no Programa de Apoio às Publicações Científicas Periódicas da USP, o que garantia a viabilidade da publicação semestral

3 Do Conselho Editorial (Comissão Executiva) de Psicologia USP, também participaram, em momentos diferentes: Eva Migliavacca, Jussara Falek Brauer, Helena Maria Sampaio Bicalho, Maria Inês Assumpção Fernandes, Nielsy Helena Puglia Bergamasco e Ana Maria Loffredo. 
da revista, não tínhamos inicialmente um setor de publicações, o apoio administrativo não era tempo integral e a verba para o pagamento de tradutores, revisores e funcionários especializados era pouca, quase virtual. Mas tínhamos a consciência da relevância do que estava sendo feito e não nos queixávamos muito por ter de arregaçar as mangas.

O setor de publicações ganhou existência oficial em 1993, em reunião do C.T.A., "após longa discussão sobre esse assunto", sob o nome de Setor de Apoio às Publicações, uma iniciativa sacramentada logo depois, em 1994, pela Congregação. O setor ficou sob a responsabilidade de Maria Clarice Ferreira, que já vinha trabalhando (intensamente), como secretária geral da revista. Em fevereiro de 1995, como Diretora do IP, Sylvia pediu ao Reitor Flávio Fava de Moraes uma mudança do organograma da Unidade que contemplasse a criação do Serviço (já não mais setor) de Edição, Publicação e Apoio à Pesquisa, do qual seria responsável Clarice, com a colaboração de Gerson da Silva Mercês. O serviço atenderia a revista Psicologia USP dentro de suas várias funções. Com o afastamento de Clarice para cuidar da pós-graduação, em 1997, Gerson é que se tornou a peça central para a produção gráfica da revista (e de outras revistas do IP, como a Revista de Etologia), além de assumir atividades de contato, produção, arquivamento, estocagem etc.

Os arquivos relativos aos artigos, antes encaminhados em formato Word (Microsoft) para a gráfica que se encarregava de produzir as matrizes, com problemas devido à passagem de um tipo de editor de texto para outro e à necessidade de um grande esforço de revisão, passaram a ser manipulados por Gerson com o programa Pagemaker e transformados em matrizes, o texto saindo da impressora laser em imagem ao espelho. O processo era mais seguro, uma vez sendo definitiva a versão produzida no Instituto. As coisas são ainda mais simples, hoje: a gráfica recebe versões em pdf, prontas para serem usadas na impressão.

As revisões dos textos, tarefa sumamente tediosa, eram feitas pelo pessoal da Comissão Executiva, mas principal e primorosamente por Sylvia e por Maria Helena, que era assistente editorial de Psicologia USP. Mais tarde, pudemos contar, para a revisão de alguns dos manuscritos, com a cooperação de Antonieta Gonçalves Gilioli, uma competente e simpática ex-professora de português da rede pública de ensino, que nos cobrava, não por página, mas 
pelo tempo, medido em minutos, gasto para a tarefa. O colega John de Souza, do Departamento de Psicologia Experimental, native speaker, e o aluno Pablo de Carvalho Godoy Castanho cuidaram da revisão dos resumos em inglês. Nunca chegou a ser cogitada a possibilidade de serem aceitos manuscritos em língua estrangeira, todos os recebidos de fora eram vertidos para o português.

A biblioteca do Instituto (Serviço de Biblioteca e Documentação) teve, desde o início, uma participação importante na produção de Psicologia USP. Uma revista tem que sair perfeita nos detalhes de citação e de referências, e esta perfeição foi alcançada graças ao trabalho do pessoal da Biblioteca e, em particular, a Aparecida Angélica Z. P. Sabadini. Lembro, além disso, os serviços prestados para a divulgação da revista, para sua distribuição dentro da rede de bibliotecas em Psicologia, para dar andamento às assinaturas, as iniciativas para alcançar indexações. Sentimo-nos sempre em casa na Biblioteca.

Nas reuniões do Conselho Editorial (chamado, a partir de 1997, Comissão Executiva), muitas vezes realizadas na sala da Sylvia, ao redor de uma mesa de cantos arredondados (era uma mesa-redonda, pelo menos no sentido do verbete do Houaiss: discussão ou conferência em que todos aqueles que dela participam estão em pé de igualdade), examinávamos a lista de manuscritos, ouvíamos o parecer de quem tivesse lido o material ou fosse responsável pela sua apresentação, planejávamos o sumário de cada número, discutindo possíveis convites a autores, e distribuíamos entre nós as tarefas necessárias. Outras questões eram abordadas, as mais delicadas tinham a ver com o nível, às vezes insatisfatório, dos manuscritos recebidos e com o aperto ou apuro de prever que poderia atrasar-se a publicação de um fascículo. A participação de Sylvia era a de um membro do grupo, nunca a vi destacar a sua posição de editora nem impor políticas de publicação, nem mesmo manifestar uma pontinha de vaidade, a não ser a vaidade de participar de um empreendimento que a todos parecia importante. É significativo que, a partir de 1997, ela tivesse desistido de colocar o seu nome em destaque, debaixo da rubrica "Editor" e o tivesse inserido entre os outros nomes, em ordem alfabética, da comissão.

Psicologia USP foi, ao longo de sua produção, adquirindo um estilo. Passou a ter um tamanho menor, mais próximo da aparência de um livro e variou os tons claros de suas capas. A bela gravura de Marcelo Grassmann (escolhida por João Augusto) que, nas primeiras edições da revista, estava centralizada na 
primeira capa, mudou-se para o lado, pegou a lombada e um pedacinho da capa traseira. Um rosto pensativo, com magnífico ornamento em forma de tiara ao redor da cabeça, sobre um fundo preto. O jeito introspectivo da figura sempre me pareceu apropriado para a Psicologia, que, desde as suas origens, sempre quis explicar as coisas da mente, partindo de um olhar dirigido para dentro. $\mathrm{O}$ que pensa a figura misteriosa de Grassmann ? Abra a revista e descubra.

Duas características foram se firmando, na maneira como concebíamos a revista. A primeira, a mais importante, era a decisão de que seria uma revista dedicada à reflexão a respeito de temas relevantes à Psicologia. Assim, se diferenciaria das revistas que publicam trabalhos empíricos, e ganharia coerência dentro de uma atitude de síntese e de crítica, mais do que nunca necessária na Psicologia. Parecia-nos importante a idéia (nem sempre posta em prática pelos periódicos da área) de que cada revista deve assumir uma opção, em termos de seu campo de atuação, não sendo um repositório para tudo o que se produz. O cerne de Psicologia USP seria a reflexão sobre temas psicológicos, do ponto de vista das teorias, das aplicações e do relacionamento com outras ciências.

"Abrir espaço para o convívio da Psicologia com outras disciplinas tem sido fio condutor constante e inspirador da Psicologia USP" (Editorial, 2001, p. 9). Esta colocação, num dos editoriais, constituiu a segunda característica mestra da revista. Não conflita com a linha seletiva de publicação, mas lhe determina a estrutura e o caráter integrativo. Escreve Sylvia, noutro editorial:

Os artigos deste número da revista estabelecem pontes entre a Psicologia e as outras Ciências Humanas. Seja a Filosofia ou a História, a Educação, a Antropologia, a Política ou a Psicanálise, todas têm algo a dizer quando se trata de temas psicológicos, como a subjetividade, a memória, a identidade sexual ou a aquisição de conhecimentos. A discussão desses temas, para ser aprofundada, deve contar com muitas vozes, trilhar, às vezes, os caminhos da indisciplina, para retornar enriquecida ao âmbito da Psicologia. (Editorial, 1998, p. 9)

Indisciplina não significa necessariamente falta de disciplina, mas saída de uma determinada disciplina. Sair e voltar, conservando a identidade.

Uma das formas por meio da qual se concretizou esta filosofia multidisciplinar foi a programação de números especiais, cuja organização era confiada a um editor convidado (ou mais de um) e que continham artigos escritos 
sob diferentes perspectivas. O primeiro, sobre o tema Família e Educação, saiu em 1992; em 1993, foi Memória; em 1994, Alteridade; em 1997, Consciência; em 1999, Inconsciente (não deixa de ser interessante a sucessão, no espaço de dois anos, de um número consagrado à consciência e outro dedicado ao inconsciente. Depois do enfoque cartesiano, uma concepção em que o cogito não é mais "o lugar da verdade do sujeito, mas o lugar do seu desconhecimento", segundo Garcia-Roza, citado por João Augusto (Frayze-Pereira, 1999, p. 10)); em 2000, saiu um número dedicado a questões de Diagnóstico e, em 2002, números sobre Psicologia e Saúde e sobre Família4 . Dossiês, como os sobre Psicanálise e Universidade e Psicologia e Razão Instrumental cumpriram a mesma função de convergência.

Falo aqui, um pouco, do volume Memória. Os artigos se ordenavam dos mais básicos e biológicos aos que lidavam mais diretamente com o comportamento humano e seus determinantes culturais. Uma ordenação inversa poderia ter sido escolhida, sem prejuízo para a idéia integradora, de uma forma talvez mais instigante. Partia-se de uma história natural da memória, ou seja, do quanto ela se deixa surpreender, em animais, nos rituais do instinto, e prosseguia-se com o enfoque psicobiológico, usando-se uma linguagem isomórfica em que a cada função cognitiva correspondem circuitos neurais e sinapses. Ia-se então para uma aplicação da psicofísica às imagens lembradas e para uma análise dos processos pelos quais as pessoas "fazem contas na cabeça" e automatizam sua memória a partir do treino. Examinava-se, depois, em que medida a teoria freudiana do inconsciente incorpora uma teoria da memória e abordava-se, numa perspectiva clínica, a modulação da memória por estados afetivos. Criar uma "anti-memória", a partir de uma análise autobiográfica, era proposta como uma forma de resgate de identidade para educadores. Em vários artigos, que iam de Bergson à história oral e à história das mentalidades, passando por Halbwachs, focalizava-se a natureza social da memória, o condicionamento social dos conteúdos, assim como, de uma forma mais essencial, dos motivos e funções da memória. Sylvia contribuiu ao volume com uma resenha do livro Fables de la mémorie. La glorieuse bataille des trois rois, em

4 Editores convidados: César Ades (Memória), César Ades e Arno Engelmann (Consciência), João Augusto Frayze-Pereira (Alteridade, Inconsciente), Jussara Falek Brauer (Diagnóstico), Rachel Rodrigues Kerbauy (Psicologia e Saúde), Belinda Mandelbaum (Família). 
que Lucette Valensi (1992) focaliza os mitos sebastianistas que se originaram com a derrota portuguesa de Alcácer Quibir. Há ambigüidade em qualquer reconstituição histórica: o que não pode ser desmentido ou fabricado passa para o plano da lenda. Assim, a morte de D. Sebastião dá origem a mitos de um retorno triunfante em futuro não especificado. Será a memória produto de nossa imaginação?, indagou Sylvia. Ela mostrou, contudo, o quanto, por trás do imaginário, a dimensão do poder se expressa na memória coletiva.

Se o exercício multidisciplinar não resolve os problemas do conhecimento, numa área, pelo menos os delimita e aponta para semelhanças inevitáveis de enfoque. Na expressão de Franco Cardini, historiador italiano que participou desse número da revista, contribui para um (criativo) "desmoronamento das cercas" disciplinares.

Para Memória, Sylvia preparou um belo editorial, no qual se nota sua maneira elegante de escrever e seu gosto pela literatura. Centrava-se na dialética entre a natureza biológica do ser humano e sua vocação, inevitavelmente - alguns diriam: biologicamente - cultural. Depois de se referir à terrível ambigüidade da memória humana, ao mesmo tempo biológica e histórica, escreve Sylvia:

uma das maiores aventuras do espírito humano é a possibilidade de reencontrarse com seus semelhantes, que viveram ontem ou há milhares de anos. Também, recuando mais no tempo, encontrar dessemelhantes, recompor a história de sua trajetória na terra e, eventualmente, de seu desaparecimento. Pegadas de animais que nos antecederam foram resguardadas pela memória da matéria bruta, e a brutalidade da matéria que, subitamente, se torna viva, manteve, intactos, até mesmo os alimentos dos habitantes de Pompéia e de Herculano, surpreendidos pela morte, mas conservados pela mesma violência que os abateu... O mesmo pode-se dizer de cada homem, de cada ser vivo, de cada célula. Também a revista, algum dia, será parte do grande caudal da memória do conhecimento, fazendo uso de uma matéria mais dúctil, a palavra, mas não menos poderosa na guarda e na transmissão do conhecimento. (Editorial, 1993, p. 7)

É notável a analogia entre a genética, elemento implícito no texto de Sylvia, e a palavra como elementos transmissores; entre as duas memórias, a antiga, social e outra mais antiga ainda, memória da espécie, faz pensar na idéia de memes, imaginada por Dawkins (1989). 
Ainda sobre a interface entre Psicologia e Biologia, escreve Sylvia:

a disciplina exigida pela Etologia ensina muitas virtudes ao pesquisador, como a paciência e a humildade. Através do estudo dos animais, aproximamo-nos da universalidade de manifestações da Vida e da pluralidade, quase infinita, de respostas que a natureza oferece aos desafios da sobrevivência. Nada convém mais ao pesquisador, na Psicologia, que essas virtudes: compreendermos o enorme esforço necessário para não injustiçar o microcosmos, que chamamos Homem, e a prudência, sempre necessária, para não isolá-lo, com soberba, no centro do universo. (Editorial, 1995, p. 9)

Buscar convergências também foi o objetivo do número Consciência. O diálogo se estabeleceu, concretamente, entre colegas de várias instituições, numa mesa-redonda e num seminário de dia inteiro realizado no Centro Universitário Maria Antônia, sendo também intermediado pelos textos apresentados. Do seminário da Maria Antônia, guardo a muito grata lembrança da participação de Lígia Marcondes Machado, que contribuira com um artigo inspirado nas idéias da análise experimental do comportamento e que, já muito doente, insistiu em comparecer e em encantar a todos com a sua palestra. E a lembrança de quão retribuído me senti por estarmos realizando o encontro, numa sala em que eu ouvira, em outras eras, a fala de Florestan Fernandes e de outros admiráveis professores. Sylvia escreveu:

recusando a dicotomia corpo/mente, (o número sobre Consciência) situa-nos, com ênfase especial na constituição biológica da consciência e de seus atributos, como o pensamento e a linguagem, no conjunto dos seres vivos com quem partilhamos, embora como Senhores desastrados, a mesma Terra. (Editorial, 1997a, p. 9)

Psicologia USP também teve por opção debater temas de interesse social e da cidadania. No editorial que introduz o número Psicologia e Razão Instrumental, está explícito o engajamento de Sylvia e de Maria Helena (de quem expressa as idéias):

Parte dos trabalhos deste número da revista Psicologia USP está voltada para a compreensão do lugar da Psicologia no universo das práticas sociais, em especial o papel dos instrumentos, sobretudo as medidas da inteligência, destinados a categorizar, organizar e distribuir os sujeito em um universo que, paradoxalmente, quer ser pensado como igual ao universo dos objetos.... A instrumentalização no domínio das práticas sociais tem como consequiência a perda do significado e do valor, a 
degradação do humano ao estatuto de coisa e a impossibilidade de estabelecer com clareza a diferença entre meios e fins. Tratar como pertencentes a campos distintos a ciência e a técnica implica separar Ética e conhecimento, cisão trágica cujas conseqüências ainda não conhecemos de todo. (Editorial, 1997b, p. 9)

Psicologia USP quis contribuir para a manutenção da memória científica, homenageando em números especiais o trabalho dos docentes notáveis do Instituto. Seu conteúdo era, em parte, história da ciência, em parte, história pessoal e lembranças, mas o que contava era manter a lembrança do pesquisador, não apenas a cronologia de sua atuação e de suas publicações. O primeiro número de homenagem, coordenado por Ana Maria Almeida Carvalho, Psicologia e Etologia ${ }^{5}$, foi dedicado ao Walter Hugo de Andrade Cunha (1995). Depois veio Psicologia e Ciência no Brasil ${ }^{6}$, sob edição de Maria Amélia Matos, dedicado a Carolina Martuscelli Bori (1998). Tanto Carolina como Maria Amélia não se encontram mais, infelizmente, entre nós. Em 2000 foi publicado o número Dante Moreira Leite ${ }^{7}$, tendo Maria Luiza Sandoval Schmidt como editora convidada. Criava-se uma tradição na qual se situam os números dedicados a Luiz Carlos Nogueira e à própria Sylvia.

O lançamento dos números de Psicologia USP não pode ficar fora do relato, só por ter sido festivo. O ciclo começava em torno de uma mesa e diante de uma pilha de manuscritos, chegava o momento em que as idéias tinham de ir ao mundo, por conta própria. E esse momento merecia ser comemorado com uma taça de vinho e salgadinhos (era certamente essa a opinião dos alunos, que gostam de comemorações, por assim dizer, substanciais). Muitos lançamentos foram realizados no saguão do Bloco 23, onde estava a Diretoria e a Administração do Instituto; outros, no salão de leitura da Biblioteca, um local denso de leituras e de informação, por isso mesmo apropriado (lembrome da emoção de lá recebermos Myriam Moreira Leite, no lançamento do número em homenagem ao Dante); outros (Psicologia e Ciência no Brasil, e Consciência), no Centro Universitário Maria Antonia, lá onde tudo começou. Um deles ocorreu, com ótimas conversas e muita animação, no bar Rosenbeef da Vila Madalena. Houve até um lançamento simbólico. A gráfica, de última hora, avisou que não poderia entregar a revista (Psicologia e Etologia) em

5 Psicologia e Etologia (1995). Editora convidada: Ana Maria Almeida Carvalho.

6 Psicologia e Ciência no Brasil (1998). Editora convidada: Maria Amélia Matos.

7 Dante Moreira Leite (2000). Editora convidada: Maria Luiza Schmidt. 
tempo para a comemoração. Não havia como desmarcar. Não podendo divulgar a revista inteira, lançamos a capa, que já tinha sido impressa !

Durante a década em que Sylvia, de um jeito tranqüilo e democrático, coordenou Psicologia USP, a revista conquistou um reconhecimento merecido. Foi um A nas avaliações CAPES (1999), foi a indexação na base de dados LILACS, foi a inclusão no rol das revistas divulgadas pela Scielo (FAPESP). Foi um aumento no número de manuscritos submetidos e um aumento no número de leitores, mais palpável depois da entrada na Scielo. A magia do acesso digital - um tecla pressionada e surge o pdf do artigo, tal qual aparece na versão impressa - projetou a revista e as idéias veiculadas por ela. Psicologia USP será um dia acessada principalmente por meio da Internet, é inevitável... Mas, então, sentirei saudade dos volumes impressos e da gravura de Grassmann, enigmática e introspectiva, na capa.

Quando, em 2000, sucedi a Lino de Macedo na Diretoria do Instituto, os membros da Comissão Executiva de Psicologia USP puseram os seus cargos à disposição, deixando-me a liberdade de montar outro grupo para a tarefa. Como Lino, quatro anos atrás, pedi sem hesitar que continuasse a comissão, insistindo especialmente junto a Sylvia, que tinha outros planos, para que permanecesse. Foi bom que tenha permanecido. Assim cuidou de uma etapa de transição, no final da qual Ana Maria Loffredo assumiu como nova editora.

O cenário da publicação científica em Psicologia transformou-se, com rapidez, durante o período que aqui abordei, talvez como nunca tivesse se transformado antes, e continua evoluindo. Aumentou o número de revistas; surgiram, ao nível da CAPES e do CNPq, instâncias qualificadoras e criadoras de normas; está se desenvolvendo um senso da inserção das publicações numa rede bem mais ampla, nacional e internacional; editores começam a interagir, discutindo critérios e políticas; novos programas informatizados começam a ser cobiçados como maneira mais prática de levar adiante a interação da revista com os seus autores e assessores. Enquanto isso, os campos de pesquisa vão se desenvolvendo e cresce a pressão da demanda por bons períodicos. São muitos os novos desafios com que se defronta Psicologia USP. Gratifica-me ter participado, com Sylvia e o resto do pessoal, da etapa prévia, aventurosa e constitutiva. 
Ades, C. (2007). Psicologia USP, 1992-2002: a participatory adventure. Psicologia USP, 17(3), 33-44.

Abstract: This article examines 10 years of production of the journal Psicologia USP (1992-2002), when under the editorship of Sylvia Leser de Mello. During this period, the basic policy of the journal was to publish critical essays on relevant psychological themes, as opposed to the publication of papers with empirical content. A multidisciplinar approach was adopted and led to the preparation of special issues (Memory, Unconscious, Psychology and Health, among others) and dossiers (Psychoanalysis and University, Psychology and Instrumental Reason, among others) in which researchers from the social and biological sciences took part, seeking for contrasts and convergencies. The journal contributed to scientific memory by publishing special issues on the work and influence of members of the Institute of Psychology ( Psychology and Ethology, Dante Moreira Leite, among others). This decade of participative effort and accomplishment played an important role in the determination of the course of the journal and prepared Psychology USP for new publishing challenges.

Index terms: Psicologia USP. Publications in Psychology. Institute of Psychology (USP).

Ades, C. (2007). Psicologia USP, 1992-2002: a participatory adventure. Psicologia USP, 17(3), 33-44.

Résumé: Dans cet article, j'évoque les dix années de production de la revue Psicologia USP (1992-2002) quand Sylvia Leser de Mello en était la rédactrice en chef. C'est dans cette période que l'objet de la revue fut défini comme étant une réflexion critique à propos de thèmes psychologiques plutôt que la publication d'articles de recherche expérimentale et que fut adoptée une perspective multidisciplinaire qui se concrétisa par l'édition de numéros spéciaux (Mémoire, Inconscient, Psychologie et Santé, parmi d'autres) et de dossiers (Psychanalyse et Université, La Psychologie et la Raison Instrumentale, parmi d'autres) auxquels participaient, à la recherche de contrastes et de convergences, des scientifiques provenant des sciences sociales et biologiques. La revue se mit au service de la permanence de la mémoire scientifique 
avec la publication de numéros spéciaux sur des professeurs de l'Institut de Psychologie ( Psychologie et Éthologie, Dante Moreira Leite, entre autres). Cette décade d'efforts et de realisations collectives fut importante pour l'établissement de l'orientation de Psicologia USP et lui fournit une base pour faire face à de nouveaux défis éditoriaux.

Mots clés: Psicologia USP. Publications en Psychologie. Institut de Psychologie (USP).

\section{Referências}

Dawkins, R. (1989). The selfish gene (New edition). Oxford: Oxford University Press.

Editorial. (1993). Psicologia USP. Memória, 4(1/2), 7.

Editorial. (1995). Psicologia USP. Psicologia e Etologia, 6(1), 9.

Editorial. (1997a). Psicologia USP. Consciência, 8(2), 9.

Editorial. (1997b). Psicologia USP. Psicologia e Razão Instrumental, 8(1), 9.

Editorial. (1998). Psicologia USP, 9(2), 9.

Editorial. (2001). Psicologia USP, 12(2), 9.

Frayze-Pereira, J. A. (1999). Editorial. Psicologia USP. Inconsciente, 10(1), 9-10.

Valensi, L. (1992). Fables de la mémorie. La glorieuse bataille des trois rois . Paris: Le Seuil. Resenha de S. L de Mello (1993). Memória ou memórias? Psicologia USP. Memória, 4(1/2), 329-335.

Recebido em: 29/01/2007

Aceito em: 06/02/2007 